\title{
CDH13 and HCRTR2 May Be Associated with Hypersomnia Symptom of Bipolar Depression: A Genome-Wide Functional Enrichment Pathway Analysis
}

\author{
Chul-Hyun Cho', Heon-Jeong Lee ${ }^{1 凶}$, Hyun Goo Woo ${ }^{2}$, Ji-Hye Choi ${ }^{2}$, \\ Tiffany A. Greenwood ${ }^{3}$, and John R. Kelsoe ${ }^{3,4}$ \\ ${ }^{1}$ Department of Psychiatry, Korea University College of Medicine, Seoul, Republic of Korea \\ 2Department of Physiology, Ajou University School of Medicine, Suwon, Republic of Korea \\ ${ }^{3}$ Department of Psychiatry, University of California San Diego, La Jolla, CA, USA \\ ${ }^{4}$ San Diego VA Healthcare System, San Diego, CA, USA
}

\begin{abstract}
Although bipolar disorder is highly heritable, the identification of specific genetic variations is limited because of the complex traits underlying the disorder. We performed a genome-wide association study of bipolar disorder using a subphenotype that shows hypersomnia symptom during a major depressive episode. We investigated a total of 2,191 cases, 1,434 controls, and 703,012 single nucleotide polymorphisms (SNPs) in the merged samples obtained from the Translational Genomics Institute and the Genetic Association Information Network. The gene emerging as the most significant by statistical analysis was rs1553441 (odds ratio $=0.4093 ; \mathrm{p}=1.20 \times 10^{-5} ; \mathrm{Permuted}$ $\left.\mathrm{p}=6.0 \times 10^{-6}\right)$. However, the $5 \times 10^{-8}$ threshold for statistical significance required in a genome-wide association study was not achieved. The functional enrichment pathway analysis showed significant enrichments in the adhesion, development-related, synaptic transmission-related, and cell recognition-related pathways. For further evaluation, each gene of the enriched pathways was reviewed and matched with genes that were suggested to be associated with psychiatric disorders by previous genetic studies. We found that the cadherin 13 and hypocretin (orexin) receptor 2 genes may be involved in the hypersomnia symptom during a major depressive episode of bipolar disorder.

Psychiatry Investig 2015;12(3):402-407
\end{abstract}

Key Words Genome-wide association study, Bipolar disorder, Hypersomnia, Functional enrichment pathway analysis, Bipolar depression.

\section{INTRODUCTION}

Bipolar disorder (BD) patients suffer from both a low physical quality and low mental quality of life, even during an euthymic period. ${ }^{1} \mathrm{BD}$ is known to be highly heritable; however, the identification of specific genetic variations resulted in limited findings. ${ }^{2,3}$ One reason for this low success rate in identifying genetic variations relies in the nature and complex traits of $\mathrm{BD} .{ }^{4}$ As a consequence, dividing $\mathrm{BD}$ into subgroups according to clinical subphenotypes is a reliable alternative ap-

Received: August 21, 2014 Revised: November 17, 2014

Accepted: November 17, 2014 Available online: July 6, 2015

$\triangle$ Correspondence: Heon-Jeong Lee, MD, PhD

Department of Psychiatry, Korea University College of Medicine, 73 Inchonro, Seongbuk-gu, Seoul 136-705, Republic of Korea

Tel: +82-2-920-6721, Fax: +82-2-929-7679, E-mail: leehjeong@korea.ac.kr

(a) This is an Open Access article distributed under the terms of the Creative Commons Attribution Non-Commercial License (http://creativecommons.org/licenses/bync/3.0) which permits unrestricted non-commercial use, distribution, and reproduction in any medium, provided the original work is properly cited. proach for future genetic studies in $\mathrm{BD} .^{5}$

Several studies suggested that dysregulation of the circadian rhythm is associated with the pathophysiology of $\mathrm{BD} .{ }^{6,7} \mathrm{In}$ general, BD patients have common specific circadian rhythmrelated clinical manifestations such as: diurnal mood variation, periodicity of manic-depressive episodes, activity changes, alteration of the secretion of hormones and other endogenous substances, and sleep disturbances. ${ }^{8-10}$ Sleep disturbances may have a negative effect on emotional regulation..$^{11}$ According to these results, it can be assumed that circadian rhythm dysregulation is very closely associated with BD. ${ }^{12}$

We hypothesized that a subphenotype group that shows hypersomnia symptom during a major depressive episode of bipolar disorder may represent a genetically distinct subtype of $\mathrm{BD}$. We tested this hypothesis using a genome-wide association (GWA) analysis between subjects that showed hypersomnia symptom during a major depressive episode of bipolar disorder (hypersomnia symptom of bipolar depression, 
HBD) and subjects that did not show hypersomnia symptom during a major depressive episode of bipolar disorder (nonhypersomnia symptom of bipolar depression, NHBD). The subject samples were of European ancestry and were genotyped as part of the Genetic Association Information Network (GAIN) by the Bipolar Genome Study (BiGS).

\section{METHODS}

\section{Subject ascertainment}

Prior to genotyping, which was part of the BiGS, the unrelated bipolar I disorder subjects of European ancestry were selected from those collected by the National Institute of Mental Health Genetics Initiative for Bipolar Disorder. All subjects provided written informed consent in accordance to protocols from local institutional review boards. The subjects were interviewed using protocols from the Diagnostic Interview for Genetic Studies (DIGS). ${ }^{13}$ Information was obtained from family informants and medical records. The information was reviewed along with the interview by a panel of experienced clinicians to obtain a final best-estimate diagnosis. Control subjects were selected after they were certified through a National Institute of Mental Health-supported contract between Dr. Pablo Gejman and Knowledge Networks, Inc. ${ }^{14}$ All subjects donated a blood sample and were given medical questionnaires. The selected controls were matched for gender and ethnicity with the BD cases. Control subjects who had a history of $\mathrm{BD}$, psychosis, or recurrent major depression were excluded from our study. The subject samples as part of the GAIN were obtained by Dr. Kelsoe who is a member of the BiGS.

\section{Genotyping and cleaning}

The first set of samples was genotyped at the Broad Institute, as part of GAIN, using the Affymetrix SNP Array 6.0 (Affymetrix; Santa Clara, CA, US) 1M SNP array. We obtained a total of 1,001 BD cases, 1,033 controls, and 724,067 single nucleotide polymorphisms (SNPs). These were available for analysis following an extensive quality control (QC) process. ${ }^{15}$ The QC process eliminated all individuals with $>10 \%$ missing data, SNPs with poor allele clustering, duplicate errors, minor allele frequencies $<0.05$, and significant deviation from Hardy-Weinberg equilibrium at $\mathrm{p}<10^{-6}$. The second set of samples was genotyped similarly to the first set of samples at the Translational Genomics Institute (TGEN) and underwent a comparable QC. From this set of samples we obtained 1,190 BD cases, 401 controls, and 728,187 SNPs available for analysis. An additional round of QC was performed on the merged samples from GAIN and TGEN. This merge resulted in a set of 703,012 SNPs that passed the imposed QC process.

\section{Phenotypes}

As part of the DIGS interview, bipolar I disorder subjects were queried as to whether they had a hypersomnia symptom during major depressive episodes. According to the answer, subjects were categorized either into the HBD or the NHBD group. Those who answered 'Unknown' to the question about hypersomnia symptom were categorized as the missing group. After filtering, there were $263 \mathrm{BD}$ subjects in the HBD group and 112 subjects in the NHBD group.

\section{Association analyses}

To assess genetic factors contributing to $\mathrm{HBD}$, we performed a genome-wide case-only analysis of HBD versus NHBD. This association analysis was performed using a logistic regression using PLINK ${ }^{16}$ with a covariance adjustment for sex and age. Adaptive permutations were performed to find the empirical significance of the results using PLINK. ${ }^{16}$

\section{SNP imputation}

Missing SNPs were imputed using the IMPUTE2 tool ${ }^{17}$ and the CEU panel of HapMap 3+1,000 Genomes Pilot haplotypes as a reference. The imputed SNPs were used for the functional enrichment pathway analysis.

\section{Functional enrichment pathway analysis}

Gene ontology analysis was performed on the gene sets harboring the identified SNPs $(\mathrm{p}<0.005)$ evaluated using the DAVID software. ${ }^{18,19}$ The enriched gene functions were identified from the HBD versus NHBD analysis using an enrichment score. To go further in our investigation, we made a list of genes of the enriched pathways and compared them with various genes that were suggested to be related to psychiatric disorders by previous genetic studies. We searched the available databases in PubMed (http://www.ncbi.nlm.nih.gov/pubmed/) and in the National Human Genome Research Institute (http:// www.genome.gov/) for genes of enriched pathways. Some of the search terms included: the name of each gene of enriched pathways and "psychiatric disorder or depression or bipolar disorder or schizophrenia or circadian rhythm”. After the review and matching, we selected genes from those of enriched pathways that were described as susceptible genes in psychiatric disorders by previous genetic studies.

\section{RESULTS}

Eighty associated SNPs with $\mathrm{p}<10^{-4}$ were identified in this present genome-wide case-only analysis. We found that rs1553441 is the gene that appeared to be the most significant after statistical analysis (odds ratio $=0.4093$, p value of $1.20 \times 10^{-5}$, Permuted $\mathrm{p}=6.0 \times 10^{-6}$ ) (Supplementary Figure 1 in the online- 
only Data Supplement). This SNP is located within a region of the gene encoding the phospholipase $\mathrm{D}$ family, member 5 (PLD5) on chromosome 1q43. However, the most significant gene of this study did not reach the $\mathrm{p}$ value of $5 \times 10^{-8}$, which is the threshold for statistical significance in a GWA. ${ }^{16}$

To determine whether the associated SNPs showed enrichment in certain functional pathways, we performed a genome-wide functional enrichment pathway analysis using the imputed data. Gene ontology functions were identified for all genes that contained SNPs associated with a significance level of $p<0.005$. The functional enrichment analysis of HBD versus NHBD showed a significant enrichment of the adhesion, development-related, synaptic transmission-related, and cell recognition-related pathways (Supplementary Table 1 in the online-only Data Supplement). We can speculate that the altered functions of these pathways may contribute to the development of hypersomnia symptom during a major depressive episode of BP.

We aimed to investigate the genes of the enriched pathways in more detail. At first, we reviewed the results of previous genetic studies of psychiatric disorders found in the PubMed database (http://www.ncbi.nlm.nih.gov/pubmed/) and the database from the National Human Genome Research Institute (http://www.genome.gov/). To search the databases we used search terms such as: the name of each gene of enriched pathways and "psychiatric disorder or major depressive disorder or bipolar disorder or schizophrenia or circadian rhythm". In accordance with previously reported genetic findings, we investigated the significant genes of those identified from cate- gories that showed significant enrichment by comparison to the results of previous genetic studies. We selected the genes of enriched pathways that matched those that have been suggested in the literature to be related to psychiatric disorders (Table 1). We ultimately found two matching genes: cadherin 13 (CDH13) and hypocretin (orexin) receptor 2 (HCRTR2). CDH13 is located in 16q24.2 and encodes a member of the cadherin superfamily. The encoded protein acts as a negative regulator of axon growth during neural differentiation. ${ }^{20,21}$ In the present pathway analysis, $\mathrm{CDH} 13$ was identified as a member of genes thought to be involved in cell adhesion, biological adhesion, cell-cell adhesion, cell projection organization, and cell motion. HCRTR2 is located in 6p12 and encodes a G protein-coupled receptor involved in regulation of feeding and sleep behavior. ${ }^{22}$ In the present pathway analysis, HCRTR2 was identified as a member of genes thought to be involved in cell-cell signaling, synaptic transmission, transmission of nerve impulse, and neurological system process.

\section{DISCUSSION}

We were not able to identify significant genes in a GWA study that evaluated HBD versus NHBD. As a consequence, we focused on the pathways identified in genome-wide functional enrichment pathway analysis that showed significant enriched function. Specifically, we evaluated the gene lists of these enriched pathways, and compared them with genes that were previously suggested in the literature to be related to psychiatric disorders. This procedure was found to be helpful in find-

Table 1. Enrichment findings of the genome-wide functional enrichment pathway analysis in hypersomnia symptom of bipolar depression

$\begin{array}{lll}\text { Annotation cluster } 1 & & \text { Enrichment score: } 6.7143 \\ \text { Term } & \text { p-value } & \text { Gene of interest } \\ \text { GO:0007155 cell adhesion } & 1.96 \times 10^{-9} & \text { CDH13 } \\ \text { GO:0022610 biological adhesion } & 2.04 \times 10^{-9} & \text { CDH13 } \\ \text { GO:0016337 cell-cell adhesion } & 0.0018 & \text { CDH13 } \\ \text { Annotation cluster } 2 & & \text { Enrichment score: } 4.0558 \\ \text { Term } & \text { p-value } & \text { Gene of interest } \\ \text { GO:0030030 cell projection organization } & 6.83 \times 10^{-5} & \text { CDH13 } \\ \text { GO:0006928 cell motion } & 0.0019 & \text { CDH13 } \\ \text { Annotation cluster } 3 & & \text { Enrichment score: } 3.2072 \\ \text { Term } & \text { p-value } & \text { Gene of interest } \\ \text { GO:0007267 cell-cell signaling } & 1.15 \times 10^{-5} & \text { HCRTR2 } \\ \text { GO:0007268 synaptic transmission } & 3.82 \times 10^{-5} & \text { HCRTR2 } \\ \text { GO:0019226 transmission of nerve impulse } & 6.47 \times 10^{-4} & \text { HCRTR2 } \\ \text { GO:0050877 neurological system process } & 0.5221 & \text { HCRTR2 }\end{array}$

A gene of interest is the result of a matching procedure based on previous genetic studies on psychiatric disorders. There were various genes identified as enriched genes of interest; however, we omitted all genes that did not overlap with the genetic findings from previously reported psychiatric genetic studies. Genes of annotation cluster 4 did not contain any genes that overlapped with previous studies, and was therefore omitted from this table. Supplementary Table 1 lists the full version of these results 
ing genes that are possibly related to $\mathrm{HBD}$, although this is an unfamiliar method and the results do not always provide an explanation on how genes are related.

$\mathrm{CDH13}$ is highly expressed in various brain regions such as the cerebral cortex, medulla, thalamus, and midbrain. ${ }^{20} \mathrm{It}$ has been suggested that $\mathrm{CDH13}$ is associated with various drug abuse-related phenotypes, ${ }^{23-28}$ especially with respect to comorbid depression and alcohol dependence. ${ }^{29}$ Disorders related to substance use, particularly alcohol dependence, show high comorbidity with $\mathrm{BD} .{ }^{30} \mathrm{In}$ addition, the presence of substance abuse disorders seriously affects the course and prognosis of $\mathrm{BD} .{ }^{31} \mathrm{CDH} 13$ expression also showed an association with adiponectin levels ${ }^{32,33}$ and depression. ${ }^{34}$ Previous studies investigated adult depressed patients that showed decreased circulating levels of adiponectin. ${ }^{35-37}$ One explanation for this finding could be that adiponectin is related to the Hypothalamic-Pituitary-Adrenal (HPA) axis. Several studies suggested a correlation between adiponectin and stress and development of various psychiatric disorders. ${ }^{38}$ Furthermore, TNF- $\alpha$, IL-10, and IL-6, previously shown to be regulated by adiponectin, also showed a correlation with BD. ${ }^{39,40}$ TNF- $\alpha$ is suggested to produce an increased slow-wave sleep and a symptom of sleepiness. ${ }^{41}$ Orexin, also known as hypocretin-A and B, neuromodulatory peptides secreted from orexin neurons, signal through orexin receptor 1 and orexin receptor 2 (HCRTR1 and HCRTR2), which are G protein-coupled receptors. ${ }^{42}$ Orexin-containing neurons project out to various monoaminergic nuclei of the brain, including the locus coeruleus (norepinephrine), the raphe nuclei (5-hydroxytryptamine, 5-HT), and the ventral tegmental area (dopamine). Therefore, the orexin-containing neurons can modify the monoaminergic neurons. ${ }^{43}$ Furthermore, the presence of a functional positive feedback loop between the orexin and monoaminergic neurons has been suggested. ${ }^{44}$ Orexin is implicated in diverse functions such as feeding, drinking, the sleep-wake cycle, hormone secretion, autonomic function, drug addiction, and reward. To date, most research has focused on the role of orexin in depression compared to other mood disorders, and several studies suggested that orexin plays a significant role in depression. ${ }^{45}$ In particular, several studies have reported a role for orexin in sleep disturbance, ${ }^{46,47}$ reward system, ${ }^{48}$ feeding behavior, ${ }^{49,50}$ hippocampal neuronal plasticity, ${ }^{51-53}$ and monoamines. ${ }^{54,55} \mathrm{It}$ is important to note that $\mathrm{BP}$ is an important portion of depressive symptoms. Moreover, atypical depressive symptoms, characterized by hypersomnia, hyperphagia (or weight gain), and leaden paralysis, are more common in patients with BP than unipolar depression. ${ }^{56}$ We speculate that representative symptoms of atypical depression, such as hypersomnia and hyperphagia, may be closely related to orexin's function. Moreover, a balanced effect of orexin's action on either the HCRTR1 or the HCRTR2 receptor is important in achieving an anti-depressant- or pro-depressant-like effect. ${ }^{57}$ Taken together, these previous findings suggest that hypersomnia symptoms during a major depressive episode of bipolar disorder are related to the functions of CDH13 and HCRTR2.

We have explored the genetic association of $\mathrm{BD}$ using the HBD subphenotype to focus on a more homogenous group of subjects that present similar clinical courses. Although the present GWA of HBD versus NHBD did not produce significant results, the functional enrichment pathway analysis identified significant enrichments of the adhesion, developmentrelated, synaptic transmission-related, and cell recognitionrelated pathways. In addition, we found that $\mathrm{CDH} 13$ and HCRTR2 show a potential correlation with HBD and we used a matching process based on the results of previous genetic studies performed on psychiatric disorders. To date, only several studies have been reported about this correlation. In the future, more studies focusing on the correlation between these pathways or several genes and $\mathrm{HBD}$ are needed to validate the results reported in the present study.

\section{Supplementary Materials}

The online-only Data Supplement is available with this article at http://dx.doi.org/10.4306/pi.2015.12.3.402.

\section{Acknowledgments}

Bipolar Genome Study Co-authors: John R. Kelsoe, Tiffany A. Greenwood, Caroline M. Nievergelt, Rebecca McKinney, Paul D. Shilling, Erin N. Smith University of California, San Diego, CA, USA; Nicholas J. Schork, Cinnamon S. Bloss - Scripps Translational Science Institute, La Jolla, CA, USA; John I. Nurnberger, Jr., Howard J. Edenberg, Tatiana Foroud, Daniel L. Koller - Indiana University, Indianapolis, IN, USA; Elliot S. Gershon, Chunyu Liu, Judith A. Badner - University of Chicago, Chicago, IL, USA; William A. Scheftner Rush University Medical Center, Chicago, IL, USA; William B. Lawson, Evaristus A. Nwulia, Maria Hipolito - Howard University, Washington, D.C., USA; William Coryell - University of Iowa, Iowa City, IA, USA; John Rice - Washington University, St. Louis, MO, USA; William Byerley - University of California, San Francisco, CA, USA; Francis J. McMahon, Thomas G. Schulze National Institute of Mental Health Intramural Research Program, Bethesda, MD, USA; Wade H. Berrettini - University of Pennsylvania, Philadelphia, PA, USA; James B. Potash, Peter P. Zandi, Pamela B. Mahon - Johns Hopkins School of Medicine, Baltimore, MD, USA; Melvin G. McInnis, Sebastian Zöllner, Peng Zhang - University of Michigan, Ann Arbor, MI, USA; David W. Craig, Szabolics Szelinger - The Translational Genomics Research Institute, Phoenix, AZ, USA; Thomas B. Barrett - Portland Veterans Affairs Medical Center, Portland, OR, USA

This work was supported by grants from the National Institute of Mental Health (NIMH) and National Human Genome Research Institute (NHGRI) to JRK (MH078151, MH081804, and MH059567supplement), and by the Genetic Association Information Network (GAIN). HJL was supported by the Korea Health 21 R\&D Project funded by the Ministry of Health \& Welfare, Republic of Korea (HI11C1901) and the Future Environmental R\&D grant funded by the Korea Environmental Industry and Technology Institute (No. RE201206020).

\section{REFERENCES}

1. Gutierrez-Rojas L, Gurpegui M, Ayuso-Mateos JL, Gutierrez-Ariza JA, 
Ruiz-Veguilla M, Jurado D. Quality of life in bipolar disorder patients: a comparison with a general population sample. Bipolar Disord 2008; 10:625-634.

2. Baum AE, Akula N, Cabanero M, Cardona I, Corona W, Klemens B, et al. A genome-wide association study implicates diacylglycerol kinase eta (DGKH) and several other genes in the etiology of bipolar disorder. Mol Psychiatry 2008;13:197-207.

3. Smith EN, Koller DL, Panganiban C, Szelinger S, Zhang P, Badner JA, et al. Genome-wide association of bipolar disorder suggests an enrichment of replicable associations in regions near genes. PLoS Genet 2011;7: e1002134.

4. Risch N, Merikangas K. The future of genetic studies of complex human diseases. Science 1996;273:1516-1517.

5. McQueen MB, Devlin B, Faraone SV, Nimgaonkar VL, Sklar P, Smoller JW, et al. Combined analysis from eleven linkage studies of bipolar disorder provides strong evidence of susceptibility loci on chromosomes 6q and 8q. Am J Hum Genet 2005;77:582-595.

6. Kripke DF, Nievergelt CM, Joo E, Shekhtman T, Kelsoe JR. Circadian polymorphisms associated with affective disorders. J Circadian Rhythms 2009;7:2.

7. McCarthy MJ, Nievergelt CM, Kelsoe JR, Welsh DK. A survey of genomic studies supports association of circadian clock genes with bipolar disorder spectrum illnesses and lithium response. PLoS One 2012; 7:e32091.

8. Kennedy SH, Kutcher SP, Ralevski E, Brown GM. Nocturnal melatonin and 24-hour 6-sulphatoxymelatonin levels in various phases of bipolar affective disorder. Psychiatry Res 1996;63:219-222.

9. Kripke DF, Mullaney DJ, Atkinson M, Wolf S. Circadian rhythm disorders in manic-depressives. Biol Psychiatry 1978;13:335-351.

10. Leibenluft E, Albert PS, Rosenthal NE, Wehr TA. Relationship between sleep and mood in patients with rapid-cycling bipolar disorder. Psychiatry Res 1996;63:161-168.

11. Harvey AG, Mullin BC, Hinshaw SP. Sleep and circadian rhythms in children and adolescents with bipolar disorder. Dev Psychopathol 2006; 18:1147-1168.

12. Mitterauer B. Clock genes, feedback loops and their possible role in the etiology of bipolar disorders: an integrative model. Med Hypotheses 2000;55:155-159.

13. Nurnberger JI Jr, Blehar MC, Kaufmann CA, York-Cooler C, Simpson SG, Harkavy-Friedman J, et al. Diagnostic interview for genetic studies. Rationale, unique features, and training. NIMH Genetics Initiative. Arch Gen Psychiatry 1994;51:849-859; discussion 863-864.

14. Sanders AR, Levinson DF, Duan J, Dennis JM, Li R, Kendler KS, et al. The Internet-based MGS2 control sample: self report of mental illness. Am J Psychiatry 2010;167:854-865.

15. Smith EN, Bloss CS, Badner JA, Barrett T, Belmonte PL, Berrettini W, et al. Genome-wide association study of bipolar disorder in European American and African American individuals. Mol Psychiatry 2009;14: 755-763.

16. Purcell S, Neale B, Todd-Brown K, Thomas L, Ferreira MA, Bender D, et al. PLINK: a tool set for whole-genome association and populationbased linkage analyses. Am J Hum Genet 2007;81:559-575.

17. Howie BN, Donnelly P, Marchini J. A flexible and accurate genotype imputation method for the next generation of genome-wide association studies. PLoS Genet 2009;5:e1000529.

18. Huang da W, Sherman BT, Lempicki RA. Bioinformatics enrichment tools: paths toward the comprehensive functional analysis of large gene lists. Nucleic Acids Res 2009;37:1-13.

19. Huang da W, Sherman BT, Lempicki RA. Systematic and integrative analysis of large gene lists using DAVID bioinformatics resources. Nat Protoc 2009;4:44-57.

20. Takeuchi T, Misaki A, Liang SB, Tachibana A, Hayashi N, Sonobe H, et al. Expression of T-cadherin (CDH13, H-Cadherin) in human brain and its characteristics as a negative growth regulator of epidermal growth factor in neuroblastoma cells. J Neurochem 2000;74:1489-1497.
21. Redies C. Cadherins in the central nervous system. Prog Neurobiol 2000;61:611-648.

22. Mignot E. A commentary on the neurobiology of the hypocretin/orexin system. Neuropsychopharmacology 2001;25(5 Suppl):S5-S13.

23. Drgon T, Montoya I, Johnson C, Liu QR, Walther D, Hamer D, et al. Genome-wide association for nicotine dependence and smoking cessation success in NIH research volunteers. Mol Med 2009;15:21-27.

24. Johnson C, Drgon T, Walther D, Uhl GR. Genomic regions identified by overlapping clusters of nominally-positive SNPs from genome-wide studies of alcohol and illegal substance dependence. PLoS One 2011; 6:e19210.

25. Hart AB, Engelhardt BE, Wardle MC, Sokoloff G, Stephens M, de Wit H, et al. Genome-wide association study of d-amphetamine response in healthy volunteers identifies putative associations, including cadherin 13 (CDH13). PLoS One 2012;7:e42646.

26. Liu QR, Drgon T, Johnson C, Walther D, Hess J, Uhl GR. Addiction molecular genetics: 639,401 SNP whole genome association identifies many "cell adhesion" genes. Am J Med Genet B Neuropsychiatr Genet 2006;141B:918-925.

27. Treutlein J, Cichon S, Ridinger M, Wodarz N, Soyka M, Zill P, et al. Genome-wide association study of alcohol dependence. Arch Gen Psychiatry 2009;66:773-784.

28. Uhl GR, Drgon T, Johnson C, Walther D, David SP, Aveyard P, et al. Genome-wide association for smoking cessation success: participants in the Patch in Practice trial of nicotine replacement. Pharmacogenomics 2010;11:357-367.

29. Edwards AC, Aliev F, Bierut LJ, Bucholz KK, Edenberg H, Hesselbrock $\mathrm{V}$, et al. Genome-wide association study of comorbid depressive syndrome and alcohol dependence. Psychiatr Genet 2012;22:31-41.

30. Merikangas KR, Akiskal HS, Angst J, Greenberg PE, Hirschfeld RM, Petukhova M, et al. Lifetime and 12-month prevalence of bipolar spectrum disorder in the National Comorbidity Survey replication. Arch Gen Psychiatry 2007;64:543-552.

31. Salloum IM, Thase ME. Impact of substance abuse on the course and treatment of bipolar disorder. Bipolar Disord 2000;2:269-280.

32. Jee SH, Sull JW, Lee JE, Shin C, Park J, Kimm H, et al. Adiponectin concentrations: a genome-wide association study. Am J Hum Genet 2010;87:545-552.

33. Wu Y, Li Y, Lange EM, Croteau-Chonka DC, Kuzawa CW, McDade TW, et al. Genome-wide association study for adiponectin levels in Filipino women identifies $\mathrm{CDH} 13$ and a novel uncommon haplotype at KNG1-ADIPOQ. Hum Mol Genet 2010;19:4955-4964.

34. Terracciano A, Tanaka T, Sutin AR, Sanna S, Deiana B, Lai S, et al. Genome-wide association scan of trait depression. Biol Psychiatry 2010; 68:811-817.

35. Leo R, Di Lorenzo G, Tesauro M, Cola C, Fortuna E, Zanasi M, et al. Decreased plasma adiponectin concentration in major depression. Neurosci Lett 2006;407:211-213.

36. Narita K, Murata T, Hamada T, Takahashi T, Kosaka H, Sudo S, et al. Adiponectin multimer distribution, not absolute amount of plasma, correlates with depression severity in healthy elderly subjects. Prog Neuropsychopharmacol Biol Psychiatry 2008;32:124-127.

37. Diniz BS, Teixeira AL, Campos AC, Miranda AS, Rocha NP, Talib LL, et al. Reduced serum levels of adiponectin in elderly patients with major depression. J Psychiatr Res 2012;46:1081-1085.

38. Taylor VH, Macqueen GM. The role of adipokines in understanding the associations between obesity and depression. J Obes 2010;2010.

39. Modabbernia A, Taslimi S, Brietzke E, Ashrafi M. Cytokine alterations in bipolar disorder: a meta-analysis of 30 studies. Biol Psychiatry 2013; 74:15-25.

40. Fernandez-Real JM, Lopez-Bermejo A, Casamitjana R, Ricart W. Novel interactions of adiponectin with the endocrine system and inflammatory parameters. J Clin Endocrinol Metab 2003;88:2714-2718.

41. Kapsimalis F, Basta M, Varouchakis G, Gourgoulianis K, Vgontzas A, Kryger M. Cytokines and pathological sleep. Sleep Med 2008;9:603- 
614

42. Sakurai T, Amemiya A, Ishii M, Matsuzaki I, Chemelli RM, Tanaka H, et al. Orexins and orexin receptors: a family of hypothalamic neuropeptides and $\mathrm{G}$ protein-coupled receptors that regulate feeding behavior. Cell 1998;92:573-585.

43. Peyron C, Tighe DK, van den Pol AN, de Lecea L, Heller HC, Sutcliffe JG, et al. Neurons containing hypocretin (orexin) project to multiple neuronal systems. J Neurosci 1998;18:9996-10015.

44. Eriksson KS, Sergeeva OA, Haas HL, Selbach O. Orexins/hypocretins and aminergic systems. Acta Physiol (Oxf) 2010;198:263-275.

45. Nollet M, Leman S. Role of orexin in the pathophysiology of depression: potential for pharmacological intervention. CNS Drugs 2013;27: 411-422.

46. Allard JS, Tizabi Y, Shaffery JP, Manaye K. Effects of rapid eye movement sleep deprivation on hypocretin neurons in the hypothalamus of a rat model of depression. Neuropeptides 2007;41:329-337.

47. Feng P, Vurbic D, Wu Z, Strohl KP. Brain orexins and wake regulation in rats exposed to maternal deprivation. Brain Res 2007;1154:163-172.

48. Nocjar C, Zhang J, Feng P, Panksepp J. The social defeat animal model of depression shows diminished levels of orexin in mesocortical regions of the dopamine system, and of dynorphin and orexin in the hypothalamus. Neuroscience 2012;218:138-153.

49. Lutter M, Krishnan V, Russo SJ, Jung S, McClung CA, Nestler EJ. Orexin signaling mediates the antidepressant-like effect of calorie restriction. J Neurosci 2008;28:3071-3075.

50. Mahler SV, Smith RJ, Moorman DE, Sartor GC, Aston-Jones G. Multi- ple roles for orexin/hypocretin in addiction. Prog Brain Res 2012;198: 79-121.

51. Ito N, Yabe T, Gamo Y, Nagai T, Oikawa T, Yamada H, et al. I.c.v. administration of orexin-A induces an antidepressive-like effect through hippocampal cell proliferation. Neuroscience 2008;157:720-732.

52. Howell OW, Doyle K, Goodman JH, Scharfman HE, Herzog H, Pringle A, et al. Neuropeptide $Y$ stimulates neuronal precursor proliferation in the post-natal and adult dentate gyrus. J Neurochem 2005;93:560-570.

53. Ito N, Yabe T, Nagai T, Oikawa T, Yamada H, Hanawa T. A possible mechanism underlying an antidepressive-like effect of Kososan, a Kampo medicine, via the hypothalamic orexinergic system in the stress-induced depression-like model mice. Biol Pharm Bull 2009;32:17161722.

54. Adidharma W, Leach G, Yan L. Orexinergic signaling mediates lightinduced neuronal activation in the dorsal raphe nucleus. Neuroscience 2012;220:201-207.

55. Pail G, Huf W, Pjrek E, Winkler D, Willeit M, Praschak-Rieder N, et al. Bright-light therapy in the treatment of mood disorders. Neuropsychobiology 2011;64:152-162.

56. Mitchell PB, Wilhelm K, Parker G, Austin MP, Rutgers P, Malhi GS. The clinical features of bipolar depression: a comparison with matched major depressive disorder patients. J Clin Psychiatry 2001;62:212-216; quiz 217.

57. Scott MM, Marcus JN, Pettersen A, Birnbaum SG, Mochizuki T, Scammell TE, et al. Hcrtr1 and 2 signaling differentially regulates depressionlike behaviors. Behav Brain Res 2011;222:289-294. 


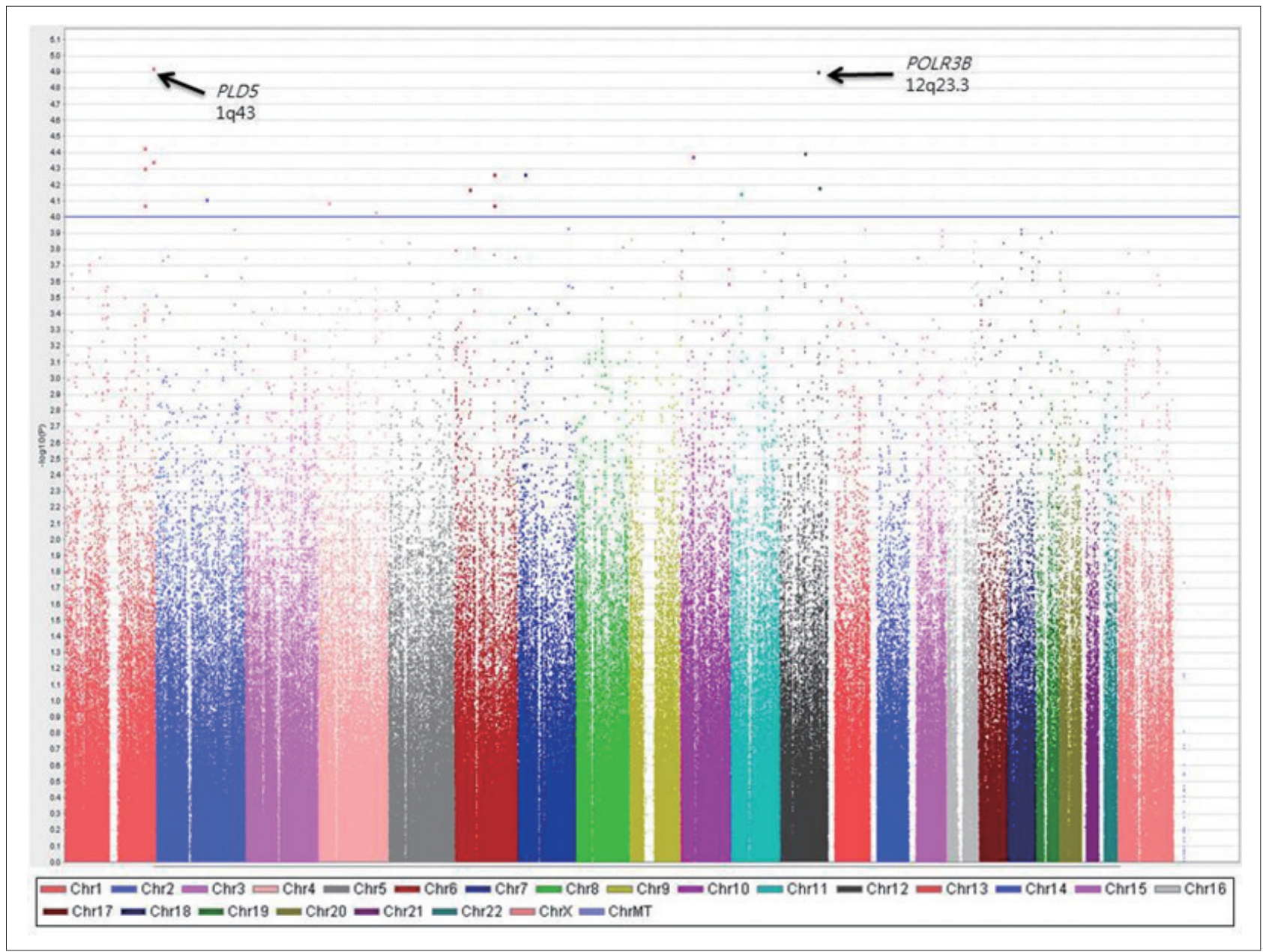

Supplementary Figure 1. Genome-wide association results for hypersomnia bipolar depression. The Manhattan plot shows the results of susceptible loci relevant to hypersomnia bipolar depression. The chromosomal position is shown along the $\mathrm{X}$-axis, whereas the -log ( $p$ value) for each single nucleotide polymorphism is shown along the Y-axis. The horizontal line indicates the $p<10^{-4}$ significance threshold. The arrows in the figure indicate the position of possible relevant genes above the set threshold. 
Supplementary Table 1. Enrichment findings from the genome-wide functional enrichment pathway analysis of hypersomnia bipolar depression

Annotation cluster 1

Term

GO:0007155

cell adhesion

GO:0022610

biological adhesion

GO:0016337

cell-cell adhesion

Annotation Cluster 2

Term

GO:0032989

cellular component

morphogenesis

\section{GO:0000904}

cell morphogenesis involved in differentiation

GO:0000902

cell morphogenesis

GO:0048667

cell morphogenesis involved in neuron differentiation

GO:0030030

cell projection organization

GO:0007411

axon guidance

GO:0048666

neuron development

GO:0007409

axonogenesis
Enrichment score: 6.7143

p-value Genes

$1.96 \times 10^{-9} \quad \underline{C D H 13}, D L C 1, N R P 2$, MTSS1, NRP1, TLN2, NELL1, CD96, CDH20, DGCR2, DAB1, CHST10, NEGR1, SYK, DLG1, PTPRM, MAGI1, CNTNAP4, CNTN5, PCDH11Y, CNTNAP5, COL22A1, CDHR3, SIGLEC10, PCDH9, CHST4, PTPRT, CTNNA3, HES1, NCAM2, ARVCF, SIRPG, LAMC3, CNTN4, RELN, CNTN3, LAMC1, SEMA4D, ADAM12, CLDN16, PLXNC1, DSCAML1, NEDD9, OTOR, ITGB1, ITGBL1, SEMA5A, FAT4, ITGB8, PVRL3, COL6A3, COL8A1, COL18A1, HAPLN1, GMDS, LPP, CD99, NID2, RAPH1, PCDH19, LAMA4, ITGA8, CYFIP2, DSC1, FCGBP, PDZD2, NTM, CDH11, MUC16

2.04×10-9 CDH13, DLC1, NRP2, MTSS1, NRP1, TLN2, NELL1, CD96, CDH20, DGCR2, DAB1, CHST10, NEGR1, SYK, DLG1, PTPRM, MAGI1, CNTNAP4, CNTN5, PCDH11Y, CNTNAP5, COL22A1, CDHR3, SIGLEC10, PCDH9, CHST4, PTPRT, CTNNA3, HES1, NCAM2, ARVCF, SIRPG, LAMC3, CNTN4, RELN, CNTN3, LAMC1, SEMA4D, ADAM12, CLDN16, PLXNC1, DSCAML1, NEDD9, OTOR, ITGB1, ITGBL1, SEMA5A, FAT4, ITGB8, PVRL3, COL6A3, COL8A1, COL18A1, HAPLN1, GMDS, LPP, CD99, NID2, RAPH1, PCDH19, LAMA4, ITGA8, CYFIP2, DSC1, FCGBP, PDZD2, NTM, CDH11, MUC16

$0.0018 \quad$ CDH13, CLDN16, DSCAML1, OTOR, ITGB1, CDH20, DAB1, FAT4, PVRL3, DLG1, SYK, PTPRM, GMDS, PCDH11Y, CDHR3, PCDH9, PTPRT, CTNNA3, PCDH19, NCAM2, ITGA8, CYFIP2, CNTN4, DSC1, CDH11

Enrichment Score: 4.0558

p-value Genes

$1.96 \times 10^{-6} \quad$ NRP2, NRP1, TFCP2L1, DSCAML1, GLI2, TTN, ITGB1, RAB3IP, SEMA5A, ATP2B2, IGF1R, CRYGB, SLC1A3, ANK1, DMD, CLASP1, UNC5C, SEMA3A, ROBO3, DLG1, COL18A1, NOX4, KLF7, PTPRM, CRYAA, RXRA, RTN4R, MYH6, HGF, WWTR1, NTN1, HES1, NCAM2, EPHA4, RELN, CNTN4, LAMC1, BMP7, SLITRK6, APBB2, GAP43

$2.09 \times 10^{-6}$

NRP2, NRP1, DSCAML1, GLI2, SEMA5A, ATP2B2, CRYGB, IGF1R, SLC1A3, SEMA3A, UNC5C, ROBO3, COL18A1, KLF7, PTPRM, CRYAA, RXRA, RTN4R, HGF, NTN1, HES1, EPHA4, NCAM2, RELN, CNTN4, LAMC1, BMP7, SLITRK6, APBB2, GAP43

$2.30 \times 10^{-6}$

NRP2, NRP1, TFCP2L1, DSCAML1, GLI2, RAB3IP, SEMA5A, ATP2B2, IGF1R, CRYGB, SLC1A3, ANK1, DMD, CLASP1, UNC5C, SEMA3A, ROBO3, DLG1, COL18A1, NOX4, KLF7, PTPRM, CRYAA, RXRA, RTN4R, HGF, WWTR1, NTN1, HES1, NCAM2, EPHA4, RELN, CNTN4, LAMC1, BMP7, SLITRK6, APBB2, GAP43

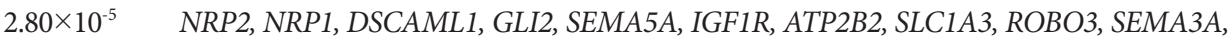
UNC5C, KLF7, PTPRM, RXRA, RTN4R, NTN1, HES1, EPHA4, NCAM2, CNTN4, RELN, BMP7, SLITRK6, APBB2, GAP43

6.83×10 $\quad$ CDH13, NRP2, MTSS1, NRP1, DSCAML1, GLI2, RAB3IP, KLHL1, SPAG16, SEMA5A, ATP2B2, IGF1R, DMD, UNC5C, SEMA3A, ROBO3, FGD5, KLF7, GNAO1, PTPRM, RXRA, RTN4R, WWTR1, NTN1, EPHA4, NCAM2, NCK1, ITGA8, TSGA10, RELN, CNTN4, BMP7, SLITRK6, APBB2, GAP43

$9.60 \times 10^{-5} \quad$ NRP2, KLF7, NRP1, PTPRM, GLI2, NTN1, SEMA5A, EPHA4, RELN, CNTN4, SEMA3A, ROBO3, UNC5C, APBB2, BMP7, GAP43

$1.71 \times 10^{-4} \quad N R P 2, N R P 1, D S C A M L 1$, GLI2, KLHL1, SEMA5A, ATP2B2, IGF1R, SLC1A3, DMD, UNC5C, SEMA3A, ROBO3, KLF7, GNAO1, PTPRM, RXRA, NTN4, RTN4R, FIG4, NTN1, HES1, EPHA4, NCAM2, NTRK2, RELN, CNTN4, BMP7, SLITRK6, APBB2, GAP43, NTM

$1.88 \times 10^{-4} \quad N R P 2, K L F 7, N R P 1, P T P R M, R X R A, R T N 4 R, D S C A M L 1$, GLI2, NTN1, SEMA5A, EPHA4, NCAM2, IGF1R, CNTN4, RELN, SEMA3A, ROBO3, UNC5C, BMP7, APBB2, SLITRK6, GAP43 
Supplementary Table 1. Enrichment findings from the genome-wide functional enrichment pathway analysis of hypersomnia bipolar depression (continued)

\begin{tabular}{|c|c|c|}
\hline $\begin{array}{l}\text { GO: } 0048812 \\
\text { neuron projection } \\
\text { morphogenesis }\end{array}$ & $2.82 \times 10^{-4}$ & $\begin{array}{l}\text { NRP2, KLF7, NRP1, PTPRM, RXRA, RTN4R, DSCAML1, GLI2, NTN1, SEMA5A, EPHA4, } \\
\text { NCAM2, IGF1R, DMD, CNTN4, RELN, SEMA3A, UNC5C, ROBO3, BMP7, APBB2, } \\
\text { SLITRK6, GAP43 }\end{array}$ \\
\hline $\begin{array}{l}\text { GO: } 0048858 \\
\text { cell projection } \\
\text { morphogenesis }\end{array}$ & $3.35 \times 10^{-4}$ & $\begin{array}{l}\text { NRP2, NRP1, DSCAML1, GLI2, RAB3IP, SEMA5A, IGF1R, DMD, SEMA3A, UNC5C, } \\
\quad \text { ROBO3, KLF7, PTPRM, RXRA, RTN4R, WWTR1, NTN1, EPHA4, NCAM2, CNTN4, } \\
\text { RELN, BMP7, SLITRK6, APBB2, GAP43 }\end{array}$ \\
\hline $\begin{array}{l}\text { GO:0030182 } \\
\text { neuron differentiation }\end{array}$ & $4.24 \times 10^{-4}$ & $\begin{array}{l}\text { NRP2, NRP1, DSCAML1, GLI2, KLHL1, SEMA5A, ATP2B2, IGF1R, SLC1A3, LHX1, DMD, } \\
\text { UNC5C, SEMA3A, ROBO3, KLF7, GNAO1, PTPRM, MDGA1, RXRA, NTN4, RTN4R, } \\
\text { VSX2, FIG4, NTN1, HES1, EPHA4, NCAM2, NTRK2, RELN, ID4, CNTN4, BMP7, } \\
\text { SLITRK6, APBB2, CLN8, NTM, GAP43 }\end{array}$ \\
\hline $\begin{array}{l}\text { GO:0031175 } \\
\text { neuron projection } \\
\text { development }\end{array}$ & $6.34 \times 10^{-4}$ & $\begin{array}{l}\text { NRP2, NRP1, DSCAML1, GLI2, KLHL1, SEMA5A, IGF1R, DMD, ROBO3, SEMA3A, } \\
\text { UNC5C, KLF7, PTPRM, GNAO1, RXRA, RTN4R, NTN1, EPHA4, NCAM2, CNTN4, } \\
\text { RELN, BMP7, SLITRK6, APBB2, GAP43 }\end{array}$ \\
\hline $\begin{array}{l}\text { GO:0032990 } \\
\text { cell part morphogenesis }\end{array}$ & $6.34 \times 10^{-4}$ & $\begin{array}{l}\text { NRP2, NRP1, DSCAML1, GLI2, RAB3IP, SEMA5A, IGF1R, DMD, SEMA3A, UNC5C, } \\
\quad \text { ROBO3, KLF7, PTPRM, RXRA, RTN4R, WWTR1, NTN1, EPHA4, NCAM2, CNTN4, } \\
\text { RELN, BMP7, SLITRK6, APBB2, GAP43 }\end{array}$ \\
\hline $\begin{array}{l}\text { GO:0006928 } \\
\text { cell motion }\end{array}$ & 0.0019 & $\begin{array}{l}\text { CDH13, NRP2, DNAH11, MTSS1, NRP1, FUT8, PLXNA2, CALD1, ABI3, MYLIP, GLI2, } \\
\text { ITGB1, SEMA5A, DAB1, UNC5C, SEMA3A, ROBO3, SYK, KLF7, PTPRM, MDGA1, } \\
\text { CHST4, NTN1, KDR, LSP1, EPHA4, IGSF8, TNS1, ETS1, BTG1, NCK1, RELN, CNTN4, } \\
\text { LAMC1, BMP7, APBB2, GAP43 }\end{array}$ \\
\hline Annotation Cluster 3 & & Enrichment Score: 3.2072 \\
\hline Term & p-value & Genes \\
\hline $\begin{array}{l}\text { GO:0007267 } \\
\text { cell-cell signaling }\end{array}$ & $1.15 \times 10^{-5}$ & $\begin{array}{l}\text { HCRTR2, SYT1, HNF1B, NRP1, GABRB3, GLRA1, SLC6A2, FGF14, GRIK4, FGF12, GLI2, } \\
\text { GJA5, SLC1A3, WNT3, GRIN2B, SLC22A3, FRS2, SYK, CLN3, GABRG3, } \\
\text { NPBWR1, CHST4, GRB10, SIRPG, SSTR1, HTR7, GRM7, WNT9B, ABAT, UNC13C, } \\
\text { CLN8, SEMA5A, LHX1, DMD, PPP3CA, SLC30A8, PCSK5, NOS1, GABRA5, HGF, } \\
\text { PARK2, ACCN1, PNOC, GRIA1, KCNN3, NTRK2, CACNA1E, RIT2, XCL1, GHSR, } \\
\text { CACNA1B, HTR2A }\end{array}$ \\
\hline $\begin{array}{l}\text { GO:0007268 } \\
\text { synaptic transmission }\end{array}$ & $3.82 \times 10^{-5}$ & $\begin{array}{l}\text { HCRTR2, SYT1, GABRB3, GLRA1, SLC6A2, GRIK4, SLC1A3, GRIN2B, DMD, SLC22A3, } \\
\text { PPP3CA, CLN3, GABRG3, NOS1, NPBWR1, GABRA5, PARK2, ACCN1, PNOC, GRIA1, } \\
\text { KCNN3, GRM7, HTR7, ABAT, CACNA1E, RIT2, UNC13C, GHSR, CLN8, HTR2A, } \\
\text { CACNA1B }\end{array}$ \\
\hline $\begin{array}{l}\text { GO:0019226 } \\
\text { transmission of nerve } \\
\text { impulse }\end{array}$ & $6.47 \times 10^{-4}$ & $\begin{array}{l}\text { HCRTR2, SYT1, GABRB3, GLRA1, SLC6A2, GRIK4, SLC1A3, GRIN2B, DMD, SLC22A3, } \\
\text { PPP3CA, CLN3, GABRG3, NOS1, NPBWR1, GABRA5, PARK2, ACCN1, PNOC, GRIA1, } \\
\text { KCNN3, GRM7, HTR7, ABAT, CACNA1E, RIT2, UNC13C, GHSR, CLN8, HTR2A, } \\
\text { CACNA1B }\end{array}$ \\
\hline $\begin{array}{l}\text { GO:0050877 } \\
\text { neurological system process }\end{array}$ & 0.5221 & $\begin{array}{l}\text { HCRTR2, RP1, SYT1, OR1J2, GABRB3, GLRA1, OR4F21, SLC6A2, GRIK4, OR1N2, SOBP, } \\
\text { ATP2B2, CRYGB, AGTR2, SLC1A3, CHST10, GRIN2B, SLC22A3, CHRNA7, KCNQ1, } \\
\text { CLN3, OR52B2, GABRG3, CRYAA, CNTN5, NPBWR1, UBR3, NCAM2, HTR7, OTOF, } \\
\text { GRM7, ABAT, UNC13C, CLN8, OTOR, PDE1C, DMD, PPP3CA, RLBP1, COL18A1, } \\
\text { NOS1, GABRA5, PARK2, VSX2, ACCN1, CHML, PNOC, GRIA1, ITGA8, KCNN3, CAC- } \\
\text { NA1E, RIT2, GHSR, VLDLR, CACNA1B, HTR2A }\end{array}$ \\
\hline Annotation Cluster 4 & & Enrichment Score: 2.4073 \\
\hline Term & p-value & Genes \\
\hline $\begin{array}{l}\text { GO:0008038 } \\
\text { neuron recognition }\end{array}$ & 0.0021 & NCAM2, NRP1, CNTN4, SEMA3A, GAP43, NTM \\
\hline $\begin{array}{l}\text { GO:0008037 } \\
\text { cell recognition }\end{array}$ & 0.0032 & CSGALNACT1, NCAM2, NRP1, COLEC12, CNTN4, FCGBP, SEMA3A, GAP43, NTM \\
\hline $\begin{array}{l}\text { GO:0007413 } \\
\text { axonal fasciculation }\end{array}$ & 0.0088 & NCAM2, NRP1, CNTN4, SEMA3A \\
\hline
\end{tabular}

The genes matched to the results reported in previous genetic studies of psychiatric disorders are emphasized in this table in bold and underlined 